\title{
Estimation of seismic moments from local magnitudes and coda durations for the Cairo earthquake aftershocks recorded at Kottamyia (KEG) Broadband station
}

\author{
El-Sayed M. Abdelrahman ( $\left.{ }^{1}\right)$, Mohamed M. Dessokey $\left({ }^{2}\right)$, Hesham M. Hussein $\left({ }^{2}\right)$ \\ and Mohamed F. Abdelwahed $\left({ }^{2}\right)$ \\ (') Cairo University, Faculty of Science, Geophysics Department, Cairo, Egypt \\ ${ }^{2}{ }^{2}$ National Research Institute of Astronomy and Geophysics (NRIAG), \\ Seismology Department, Helwan, Cairo, Egypt
}

\begin{abstract}
The spectral analysis of fifty-five KEG VBB records from the October 12, 1992 Cairo earthquake source region was performed to obtain the seismic moment. We obtained this parameter in turn to develop empirical local magnitude $\left(M_{L}\right)$, seismic moment $\left(M_{o}\right)$, coda duration $(D)$ relations for that region. In this study the data consist of $L_{g}$-waves on the vertical component seismograms for the recorded earthquakes with $M_{L}$ ranging from 1.7 to 4.7. The derived empirical relation between the seismic moment $\left(M_{o}\right)$ and magnitude $M_{L}$ for the aftershocks sequence with $1.7 \leq M_{L}<3.5$ is $\log \left(M_{o}\right)=(0.96 \pm 0.05) M_{L}+(17.88 \pm 0.13)$. We found a correlation between the coda duration $(D)$ and $\log$ of the moment $\left(\log \left(M_{o}\right)\right)$ as follows: $\log \left(M_{o}\right)=(2.35 \pm 0.27) \log (D)+(16.33 \pm 0.48)$.
\end{abstract}

Key words aftershocks - seismic moment - scaling

\section{Introduction}

On 12th of October 1992 a moderate size earthquake of $M_{w}=5.8$ occurred at epicentral distance of about $25 \mathrm{~km}$ south west of Cairo city downtown in Dahshour region (fig. 1) at a depth of $22 \mathrm{~km}$. This earthquake was felt from Alexandria to Aswan. It registered a maximum observed intensity of $7+$ in MSK intensity scale in Dahshour region (Maamoun et al., 1993). This shock caused considerable

Mailing address: Dr. Hesham M. Hussein, National Research Institute of Astronomy and Geophysics (NRIAG), Seismology Department, Helwan 11421, Cairo, Egypt; e-mail: hesham6511421@yahoo.com damage to the buildings in the eastern part of Cairo, Giza and the northern area of Fayoum. Significant damage was found mostly in adobe and old non-reinforced brick masonry buildings and non-engineering reinforced concrete buildings. In addition, extensive liquefaction of deltaic silty sand deposits (sand plumes) was observed in some cultivated fields of Giza Governerate located $19 \mathrm{~km}$ from the epicenter. According to eyewitnesses, sand and water continuously blew up to a height of $3 \mathrm{~m}$ for about $45 \mathrm{~min}$ (Maamoun et al., 1993).

The October 12, 1992 Cairo earthquake struck a previously known low seismicity zone. The only significant earthquake reported in this region during the historical period occurred in 1847. This mainshock was followed by an aftershock sequence. Within twenty two days after the occurrence of the Cairo earth- 
quake 55 shocks with $1.7 \leq M_{L} \leq 4.7$ were recorded by Kottamiya (KEG) Broadband station. The event data are given in table I. Figure 1 shows the distribution of the well located aftershocks of 1992 Cairo earthquake. Aftershocks sequence was recorded by a temporary seismic network installed by National Research Institute of Astronomy and Geophysics during the first twenty days of this sequence. Details about the seismic network and the procedure for determination of the hypocenters were described by Abou El Enein et al. (2000). However, the pattern of the aftershocks reflects a cluster rather than a clear trend of seismicity.

Teleseismic body wave inversion of the mainshock (Hussein, 1999) suggested a normal faulting mechanism with a small strike slip component on a plane striking EW to WNW-ESE and dipping to the east (fig. 1).

The purpose of this study is to calculate the seismic moments of Cairo earthquake aftershocks recorded by the KEG Broadband station during the first three weeks after the occurrence of the mainshock using the ground displacement spectra of $L_{g}$ waves and to develop empirical formulas for estimating $M_{o}$ from both $M_{L}$ and coda duration.

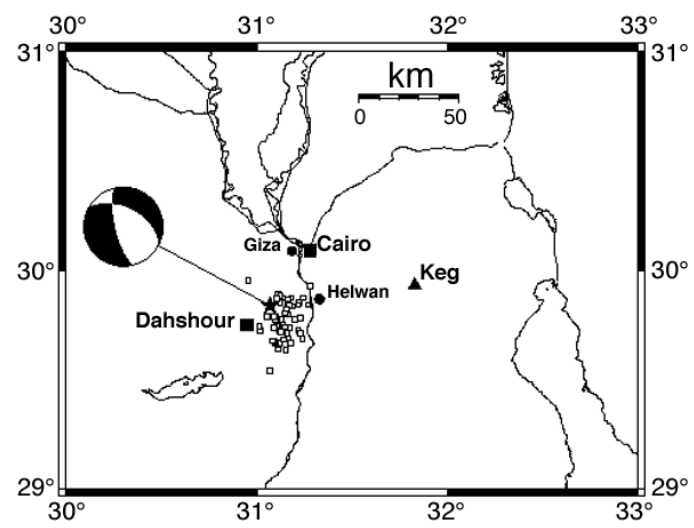

Fig. 1. Aftershocks of Dahshour earthquake of 1992 (open squares). The fault plane solution of the main shock (star) is also shown.

\section{Data}

Fifty-five Cairo earthquake aftershock sequences recorded during the three weeks after the occurrence of the mainshock of the October 12, 1992 earthquake were used in this study. Event data are given in table I. The local magnitude $\left(M_{L}\right)$ of these events varied from 1.7 to 4.7. All of these earthquakes are of crustal origin. Figure 1 shows the location of KEG station. KEG station is a part of the MEDNET project (Gardini et al., 1992). The seismic records were electronically digitized at a rate of 20 samples per second by STS-1 VBB velocity type sensor. For frequencies between 0.003 and $7 \mathrm{~Hz}$ the velocity response is flat with a full dynamic range of $140 \mathrm{~dB}$. KEG station was the only available digital recording station in Northeast Africa and Egypt in 1992.

\section{Method of analysis}

In this work, a time window that started shortly before the $L_{g}$ arrival, depending on the size of earthquake was obtained from the vertical component seismometer of KEG STS-1 VBB. The time window was nearly $10 \mathrm{~s}$ long. The digital data within the time window were corrected for the instrumental response, transformed to frequency domain using fast Fourier transformation. This spectrum was then integrated to obtain the displacement spectra. Typical spectrum examples are shown in fig. 2.

The spectrum was corrected for attenuation by multiplying it by the transfer function $e^{-\gamma r}$ where $r$ is the distance from the source to the receiver and $\gamma$ is the coefficient of anelastic attenuation which is related to the quality factor $Q$ (Nuttli, 1986)

$$
\gamma=\frac{\pi \cdot f}{U \cdot Q}
$$

$f$ is the wave frequency and $U$ is the $L_{g}$-wave group velocity. Dessokey et al. (2000) obtained the $\gamma$ value of $0.001497 \mathrm{~km}^{-1}$ for $1 \mathrm{~Hz} L_{g}$ in Dahshour region.

From the corrected spectrum, the low frequency spectral level was estimated. The low frequency level $\left(\Omega_{o}\right)$ was estimated visually by fitting a straight line at the low frequency spectra. 
Seismic moments estimation

Table I. List of earthquakes used in this study.

\begin{tabular}{|c|c|c|c|c|c|c|c|c|}
\hline \multirow{2}{*}{$\begin{array}{c}\text { Event } \\
\text { No. }\end{array}$} & \multirow{2}{*}{$\begin{array}{l}\text { Date } \\
\text { y.m.d }\end{array}$} & \multicolumn{2}{|c|}{ Origin time } & \multirow{2}{*}{$\begin{array}{l}\text { Lat. } \\
{ }^{\circ} \mathrm{N}\end{array}$} & \multirow{2}{*}{$\begin{array}{l}\text { Long. } \\
{ }^{\circ} \mathrm{E}\end{array}$} & \multirow{2}{*}{$\begin{array}{c}\text { Depth } \\
(\mathrm{km})\end{array}$} & \multirow{2}{*}{$\begin{array}{c}M_{D} \\
(\mathrm{HLW})\end{array}$} & \multirow[t]{2}{*}{$M_{L}$} \\
\hline & & $\mathrm{h}$ & $\min s$ & & & & & \\
\hline 1 & 1992.10 .12 & 13 & $50 \quad 9.65$ & $29-46.94$ & $31-13.66$ & 10.93 & & 2.5 \\
\hline 2 & 1992.10 .12 & 14 & 118.64 & $29-43.33$ & $31-9.12$ & 18.84 & & 2.3 \\
\hline 3 & 1992.10 .12 & 14 & 157.43 & $29-57.23$ & $30-57.28$ & 25.09 & & 2.8 \\
\hline 4 & 1992.10 .12 & 14 & $58 \quad 14.73$ & $29-52.55$ & $31-14.55$ & 22.32 & & 1.8 \\
\hline 5 & 1992.10 .12 & 15 & 0742.05 & $29-53.52$ & $31-6.80$ & 26.85 & & 2.3 \\
\hline 6 & 1992.10 .12 & 15 & 2524.65 & $29-52.48$ & $31-6.83$ & 29.55 & & 4.7 \\
\hline 7 & 1992.10 .12 & 15 & 5250.77 & $29-51.24$ & $31-9.94$ & 22.77 & & 2.3 \\
\hline 8 & 1992.10 .12 & 16 & $\begin{array}{ll}55 & 9.79\end{array}$ & $29-50.29$ & $31-11.01$ & 25.59 & & 2.4 \\
\hline 9 & 1992.10 .12 & 18 & 3142.36 & $29-47.89$ & $31-9.82$ & 21.14 & & 2.2 \\
\hline 10 & 1992.10 .12 & 19 & 5559.20 & $29-51.15$ & $31-13.38$ & 19.10 & & 2.2 \\
\hline 11 & 1992.10 .12 & 21 & 3134.22 & $29-40.00$ & $31-7.06$ & 20.73 & & 4.2 \\
\hline 12 & 1992.10 .12 & 21 & 4616.02 & $29-43.61$ & $31-13.10$ & 9.83 & 2.9 & 2.5 \\
\hline 13 & 1992.10 .12 & 23 & 3422.50 & $29-55.72$ & $31-16.90$ & 17.10 & 3.0 & 2.7 \\
\hline 14 & 1992.10 .12 & 23 & 4624.42 & $29-44.40$ & $31-10.38$ & 21.78 & 2.9 & 2.1 \\
\hline 15 & 1992.10 .13 & 18 & 098.14 & $29-52.44$ & $31-10.98$ & 22.39 & 3.4 & 3.7 \\
\hline 16 & 1992.10 .13 & 18 & 3454.26 & $29-50.62$ & $31-13.15$ & 20.72 & & 3.2 \\
\hline 17 & 1992.10 .13 & 23 & 2756.39 & $29-53.00$ & $31-7.37$ & 32.02 & 2.4 & 2.2 \\
\hline 18 & 1992.10 .14 & 02 & 4423.14 & $29-52.16$ & $31-9.69$ & 30.25 & 3.1 & 2.8 \\
\hline 19 & 1992.10 .14 & 03 & 5014.53 & $29-46.63$ & $31-6.43$ & 29.49 & 3.4 & 2.8 \\
\hline 20 & 1992.10 .14 & 09 & 4027.04 & $29-43.49$ & $31-1.28$ & 27.64 & 4.0 & 4.2 \\
\hline 21 & 1992.10 .14 & 10 & 4157.34 & $29-46.67$ & $31-7.99$ & 22.95 & 2.6 & 1.9 \\
\hline 22 & 1992.10 .14 & 12 & 0915.72 & $29-43.34$ & $31-5.99$ & 20.53 & & 3.0 \\
\hline 23 & 1992.10 .14 & 13 & 4639.47 & $29-50.45$ & $31-10.37$ & 28.51 & 3.5 & 3.2 \\
\hline 24 & 1992.10 .14 & 14 & 2344.67 & $29-41.18$ & $31-14.42$ & 20.22 & 3.1 & 2.4 \\
\hline 25 & 1992.10 .14 & 14 & 3127.90 & $29-43.41$ & $31-6.98$ & 24.97 & 3.3 & 2.9 \\
\hline 26 & 1992.10 .14 & 20 & 1611.05 & $29-49.25$ & $31-9.74$ & 20.94 & 2.6 & 2.3 \\
\hline 27 & 1992.10 .15 & 12 & 1341.41 & $29-48.25$ & $31-9.02$ & 25.52 & 2.6 & 2.0 \\
\hline 28 & 1992.10 .16 & 03 & 2851.46 & $29-47.29$ & $31-5.79$ & 24.12 & 2.5 & 2.0 \\
\hline 29 & 1992.10 .16 & 05 & 5611.84 & $29-47.31$ & $31-3.17$ & 30.70 & 3.1 & 2.9 \\
\hline 30 & 1992.10 .16 & 09 & 5746.87 & $29-47.50$ & $31-5.51$ & 26.25 & 3.3 & 3.1 \\
\hline 31 & 1992.10 .16 & 18 & 0753.12 & $29-51.50$ & $31-7.49$ & 24.20 & 2.6 & 2.4 \\
\hline 32 & 1992.10 .17 & 01 & 3528.51 & $29-45.06$ & $31-8.25$ & 25.44 & 2.6 & 2.0 \\
\hline 33 & 1992.10 .18 & 08 & 1216.12 & $29-43.38$ & $31-8.40$ & 20.74 & 3.4 & 2.9 \\
\hline 34 & 1992.10 .18 & 13 & 0428.44 & $29-42.75$ & $31-13.80$ & 18.50 & 3.0 & 2.6 \\
\hline 35 & 1992.10 .19 & 10 & 4630.95 & $29-42.67$ & $31-9.58$ & 21.58 & 2.9 & 2.2 \\
\hline 36 & 1992.10 .19 & 12 & 3016.44 & $29-44.22$ & $31-6.30$ & 25.20 & 3.2 & 3.0 \\
\hline 37 & 1992.10 .19 & 14 & 5950.43 & $29-44.50$ & $31-8.87$ & 18.68 & 3.3 & 3.2 \\
\hline 38 & 1992.10 .20 & 06 & 0030.77 & $29-32.36$ & $31-4.27$ & 22.28 & 2.7 & 1.7 \\
\hline 39 & 1992.10 .20 & 17 & 2828.44 & $29-40.39$ & $31-9.24$ & 20.62 & 2.5 & 2.0 \\
\hline 40 & 1992.10 .20 & 23 & 1447.46 & $29-43.08$ & $31-7.65$ & 17.20 & 3.1 & 3.1 \\
\hline 41 & 1992.10 .21 & 18 & 0927.53 & $29-46.47$ & $31-2.00$ & 14.65 & 2.7 & 2.0 \\
\hline 42 & 1992.10 .22 & 08 & 2858.70 & $29-44.83$ & $31-6.53$ & 21.90 & 3.4 & 3.4 \\
\hline 43 & 1992.10 .22 & 17 & 3857.30 & $29-40.62$ & $31-5.68$ & 22.88 & 3.9 & 4.6 \\
\hline 44 & 1992.10 .23 & 02 & $40 \quad 5.43$ & $29-44.21$ & $31-5.46$ & 22.85 & 2.6 & 2.2 \\
\hline 45 & 1992.10 .23 & 15 & 1210.08 & $29-41.39$ & $31-10.00$ & 22.40 & 3.8 & 3.3 \\
\hline 46 & 1992.10 .23 & 16 & $02 \quad 4.12$ & $29-44.78$ & $31-7.38$ & 21.70 & 2.4 & 1.7 \\
\hline 47 & 1992.10 .25 & 09 & $05 \quad 4.64$ & $29-40.09$ & $31-10.71$ & 22.05 & 3.1 & 2.8 \\
\hline 48 & 1992.10 .25 & 12 & 2615.06 & 29-39.93 & $31-5.95$ & 24.12 & 3.1 & 2.7 \\
\hline 49 & 1992.10 .25 & 16 & 2105.28 & $29-38.35$ & $31-6.70$ & 22.92 & 2.9 & 2.3 \\
\hline 50 & 1992.10 .25 & 19 & 4534.56 & $29-40.97$ & $31-8.52$ & 23.78 & 2.3 & 3.2 \\
\hline 51 & 1992.10 .26 & 06 & 4523.96 & $29-52.40$ & $31-6.49$ & 27.45 & 3.4 & 3.3 \\
\hline 52 & 1992.10 .26 & 08 & 4352.01 & $29-40.55$ & $31-5.75$ & 28.25 & 2.8 & 2.4 \\
\hline 53 & 1992.10 .28 & 06 & 2054.90 & $29-37.30$ & $31-3.63$ & 24.63 & 2.9 & 2.5 \\
\hline 54 & 1992.10 .28 & 18 & 2556.28 & $29-50.64$ & $31-16.07$ & 19.46 & 2.8 & 2.5 \\
\hline 55 & 1992.10 .30 & 14 & 0811.19 & $29-40.70$ & $31-5.09$ & 25.71 & 3.0 & 2.7 \\
\hline
\end{tabular}



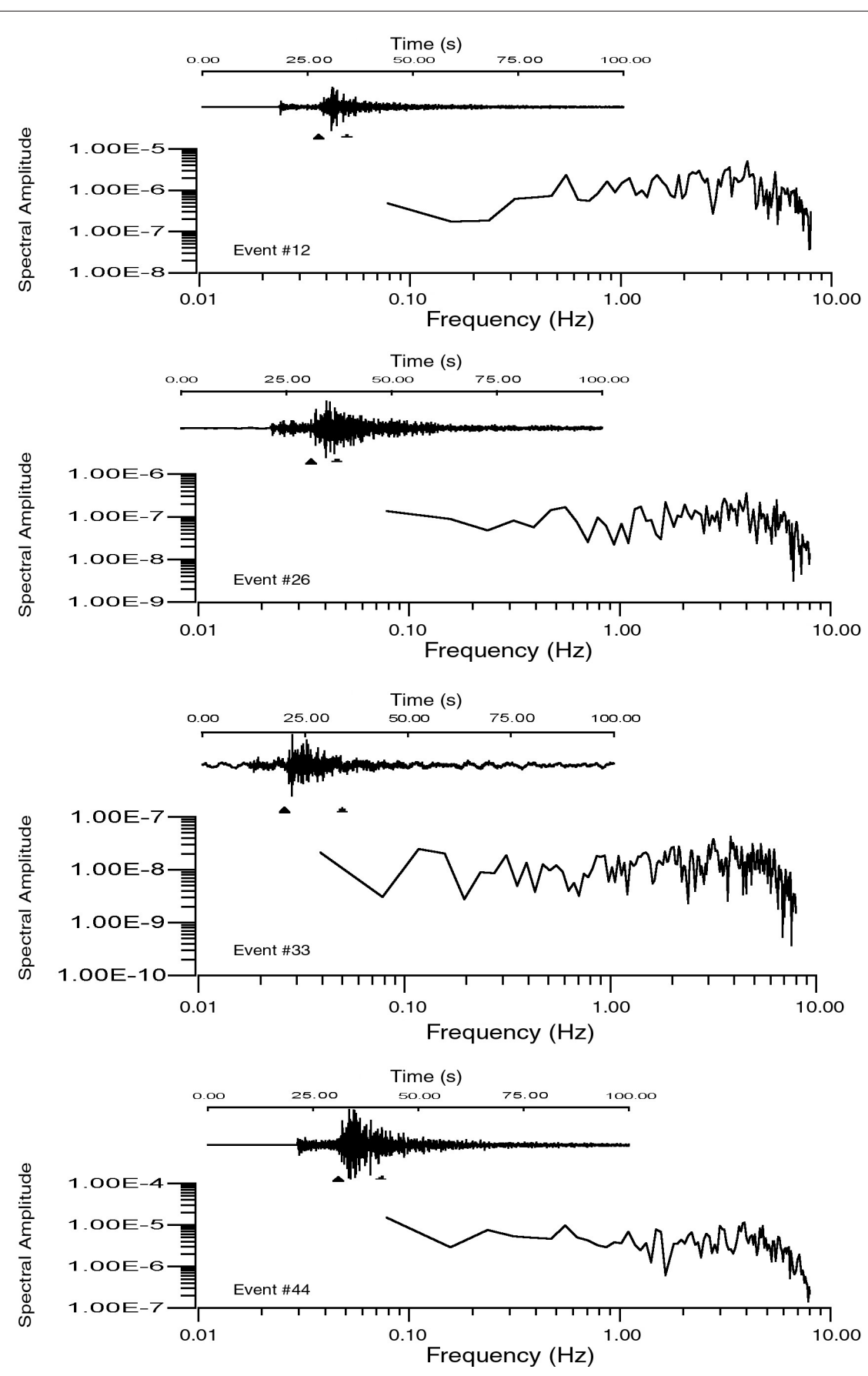

Fig. 2. Displacement spectra for $L_{g}$-waves for some selected events. 
The seismic moments $\left(M_{o}\right)$ were derived for the 55 recorded events from the low spectral level $\left(\Omega_{o}\right)$ using Street et al. (1975)'s formula that was subsequently derived by means of theoretical model by Herrmann and Kijko (1983)

$$
\begin{array}{cc}
M_{o}=4 \pi \rho \beta^{3} R_{o}\left(R / R_{o}\right) \Omega_{o} & R<R_{o} \\
M_{o}=4 \pi \rho \beta^{3} R_{o}\left(R / R_{o}\right)^{1 / 2} \Omega_{o} & R \geq R_{o}
\end{array}
$$

where $\rho$ is the density of the medium, $\beta$ is the shear wave velocity, $R$ is the epicentral distance and $R_{o}$ is the reference distance. The reference distance $R_{o}$ is related to different kinds of $L_{g}$ waves geometric spreading.

\section{Results}

\subsection{Seismic moment coda duration and local magnitude}

The seismic moment $M_{o}$ is a measure of an earthquake strength defined in terms of parameters of double couple shear dislocation source model (Aki, 1966). It provides a better description of the real size of an earthquake.

On the basis of previous empirical results, the seismic moments of the events under study were estimated using eq. (3.2). Constant values corresponding to Cairo earthquake source region in eq. (3.2) were selected as follows: $\rho=2.7 \mathrm{gm} / \mathrm{cm}^{3}, \beta=3.5 \mathrm{~km} / \mathrm{s}$ and $R_{o}=100 \mathrm{~km}$. The seismic moment estimated was found to range from $3.5 \times 10^{19}$ to $2.5 \times 10^{22}$ dyne. $\mathrm{cm}$. The calculated seismic moments using eq. (3.2) are listed in table II.

The scatter for the events having a duration longer than $108 \mathrm{~s}$ (fig. 3) is due to the small number of longer duration shocks. To obtain a more appropriate relation between the moment and the duration, a mathematical regression between the reported seismic moments and the corresponding coda durations $D$ was made for $30 \leq D \leq 108 \mathrm{~s}$. The coda duration in seconds used in this study was obtained from the available analog seismographic stations installed at the time of the earthquake. It was taken from the $P$ arrival to the point in the coda where the seismic amplitude is nearly twice the back-

\begin{tabular}{|c|c|c|c|}
\hline $\begin{array}{l}\text { Event } \\
\text { No. }\end{array}$ & $\begin{array}{l}\text { Duration } \\
\text { (s) }\end{array}$ & $M_{L}$ & $\begin{array}{c}M_{o} \\
(\text { dyne } \cdot \mathrm{cm})\end{array}$ \\
\hline 1 & & 2.5 & $1.942783 \mathrm{E}+20$ \\
\hline 2 & & 2.3 & $2.267175 E+20$ \\
\hline 3 & & 2.8 & $2.836813 \mathrm{E}+20$ \\
\hline 4 & & 1.8 & $5.468023 \mathrm{E}+19$ \\
\hline 5 & & 2.3 & $7.922314 \mathrm{E}+19$ \\
\hline 6 & 279 & 4.7 & $2.267175 \mathrm{E}+22$ \\
\hline 7 & & 2.3 & $8.386375 E+19$ \\
\hline 8 & & 2.4 & $1.225617 \mathrm{E}+20$ \\
\hline 9 & & 2.2 & $1.28611 \mathrm{E}+20$ \\
\hline 10 & & 2.2 & $1.520192 \mathrm{E}+20$ \\
\hline 11 & 169 & 4.2 & $7.825914 \mathrm{E}+21$ \\
\hline 12 & 57 & 2.5 & $1.021348 \mathrm{E}+20$ \\
\hline 13 & 65 & 2.7 & $7.1504 \mathrm{E}+20$ \\
\hline 14 & & 2.1 & $8.689964 \mathrm{E}+19$ \\
\hline 15 & 161 & 3.7 & $2.028367 \mathrm{E}+21$ \\
\hline 16 & 1992 & 3.2 & $7.671786 \mathrm{E}+20$ \\
\hline 17 & 37 & 2.2 & $6.70293 E+19$ \\
\hline 18 & 56 & 2.8 & $3.1557 \mathrm{E}+20$ \\
\hline 29 & & 2.8 & $4.717935 \mathrm{E}+20$ \\
\hline 20 & 237 & 4.2 & $5.429151 \mathrm{E}+21$ \\
\hline 21 & & 1.9 & $5.667937 \mathrm{E}+19$ \\
\hline 22 & 34 & 3.0 & $3.666106 \mathrm{E}+20$ \\
\hline 23 & & 3.2 & $4.157197 E+20$ \\
\hline 24 & & 2.4 & $4.071058 \mathrm{E}+20$ \\
\hline 25 & 69 & 2.9 & $4.769604 \mathrm{E}+20$ \\
\hline 26 & 45 & 2.3 & $6.387174 \mathrm{E}+19$ \\
\hline 27 & 35 & 2.0 & $6.550127 \mathrm{E}+19$ \\
\hline 28 & & 2.0 & $3.571662 \mathrm{E}+19$ \\
\hline 29 & 108 & 2.9 & $5.07458 \mathrm{E}+20$ \\
\hline 30 & 62 & 3.1 & $7.187676 \mathrm{E}+20$ \\
\hline 31 & & 2.4 & $2.237957 \mathrm{E}+20$ \\
\hline 32 & 35 & 2.0 & $6.845436 \mathrm{E}+19$ \\
\hline 33 & 78 & 2.9 & $4.614945 E+20$ \\
\hline 34 & 63 & 2.6 & $3.037181 \mathrm{E}+20$ \\
\hline 35 & 39 & 2.2 & $9.024836 \mathrm{E}+19$ \\
\hline 36 & 85 & 3.0 & $7.510935 \mathrm{E}+20$ \\
\hline 37 & 79 & 3.2 & $6.659202 E+20$ \\
\hline 38 & & 1.7 & $2.856025 \mathrm{E}+19$ \\
\hline 39 & 30 & 2.0 & $5.832978 \mathrm{E}+19$ \\
\hline 40 & 87 & 3.1 & $9.421127 \mathrm{E}+20$ \\
\hline 41 & & 2.0 & $6.235795 E+19$ \\
\hline 42 & 94 & 3.4 & $1.637872 E+21$ \\
\hline 43 & & 4.6 & $2.522325 \mathrm{E}+22$ \\
\hline 44 & 34 & 2.2 & $1.227609 \mathrm{E}+20$ \\
\hline 45 & & 3.3 & $1.490997 \mathrm{E}+21$ \\
\hline 46 & & 1.7 & $3.499786 \mathrm{E}+19$ \\
\hline 47 & 55 & 2.8 & $4.527036 \mathrm{E}+20$ \\
\hline 48 & 68 & 2.7 & $5.052129 \mathrm{E}+20$ \\
\hline 49 & 38 & 2.3 & $1.011922 \mathrm{E}+20$ \\
\hline 50 & & 3.2 & $7.076904 \mathrm{E}+20$ \\
\hline 51 & 99 & 3.3 & $1.602396 \mathrm{E}+21$ \\
\hline 52 & 34 & 2.4 & $1.00893 \mathrm{E}+20$ \\
\hline 53 & 59 & 2.5 & $2.729787 \mathrm{E}+20$ \\
\hline 54 & 50 & 2.5 & $1.03903 \mathrm{E}+20$ \\
\hline 55 & & 2.7 & $3.834036 \mathrm{E}+20$ \\
\hline
\end{tabular}

Table II. Seismic moment of the events under study. 


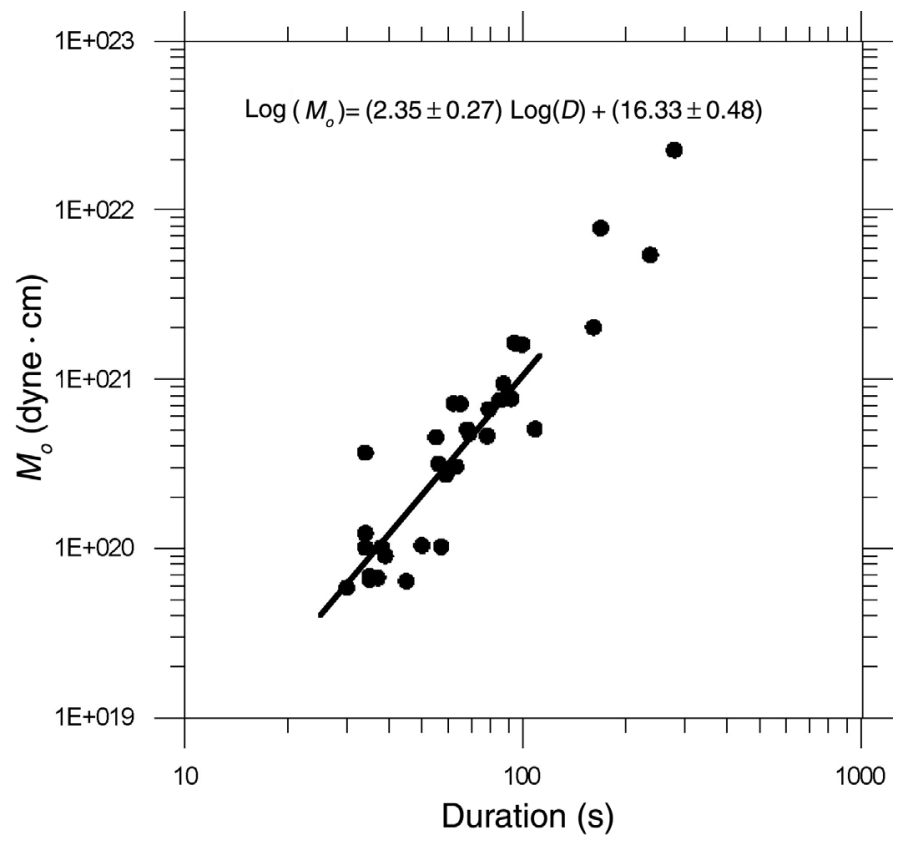

Fig. 3. Seismic moment $\left(M_{o}\right)$-coda duration relation of Dahshour aftershocks.

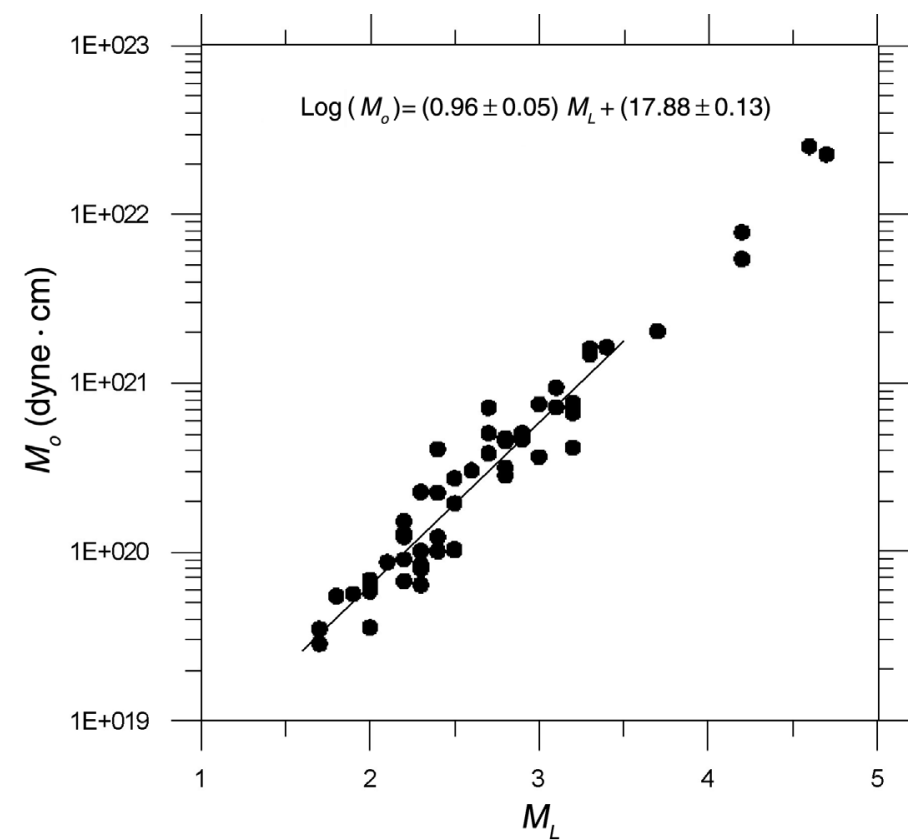

Fig. 4. Plot of seismic moment versus local magnitude. 
ground noise amplitude. The linear regression fitting of the data as shown in fig. 3 indicates the following relation:

$$
\begin{aligned}
& \log \left(M_{o}\right)=(2.35 \pm 0.27) \log (D)+ \\
& +(16.33 \pm 0.48) \quad(30 \leq D \leq 108)
\end{aligned}
$$

Estimation of seismic moment from a simple parameter such as coda duration is very useful, as it allows the estimation of the source size of local earthquakes for the moment range $3.5 \times 10^{19}$ to $1.6 \times 10^{21}$ dyne $\cdot \mathrm{cm}$. Our linear moment magnitude relation over the available duration range results in mean root square error of 0.05 in $\log \left(M_{o}\right)$. The obtained relation for all the available moment range is insufficient for meaningful comparison with the published $\log \left(M_{o}\right)$ - $\log (D)$ relations in different tectonic provinces.

The seismic moment-local magnitude relation of the form $\log \left(M_{o}\right)=C M_{L}+D$ should be carried out carefully (Shapira and Hofstetter, 1993). Bakum (1984) and Hanks and Boore (1984) detected a change in $C$ value in this relation at $M_{L} \approx 3.5$, usually undetected due to a large number of $M_{L}<5.0$ and relatively small number of $M_{L}>5.0$ earthquakes. Using these recommendations, the moment magnitude relation is obtained for the selected 50 earthquakes in the range $1.7 \leq M_{L}<3.5$. In this work, a change in the moment magnitude relation at $M_{L} \approx 3.5$ could not be observed due to small number of larger events. Figure 4 shows the seismic moment versus local magnitude $M_{L}$. The least square fitting gives the following equation:

$$
\begin{gathered}
\log \left(M_{0}\right)=(0.96 \pm 0.05) M_{L}+ \\
+(17.88 \pm 0.13) \quad\left(1.7 \leq M_{L}<3.5\right)
\end{gathered}
$$

This relation is valid for earthquakes with $1.7 \leq$ $\leq M_{L}<3.5$ and seismic moment in the range $3.5 \times 10^{19}$ to $1.6 \times 10^{21} \mathrm{dyne} \cdot \mathrm{cm}$. The average root mean square difference in the estimated $\log \left(M_{o}\right)$ is 0.028 . The relation is in a fair agreement with $\log M_{o}=1.1 M_{L}+17.9$ for $M_{L} \leq 4.1$, this relation was obtained by Fletcher et al. (1984) for aftershocks of
Orville, California earthquake. Performing a least square fitting of $\log M_{o}$ versus $M_{L}$ for $M_{L} \leq 4.1$ yields almost identical values to eq. (4.2) $\log \left(M_{o}\right)=(0.95 \pm 0.05) M_{L}+(17.90 \pm$ $\pm 0.13)$. The slope of the least square fitting between $\log \left(M_{o}\right)$ and $M_{L}$ is near one. A slope of about 1.0 for the moment-magnitude relationship seems to be similar to those obtained in many proposed moment magnitude relations for Mammoth lakes, California (Archuleta et al., 1982), Oroville, California (Fletcher et al., 1984), Hawaii (Savage and Mayer, 1985), California (Chen and Chen, 1989), Baltic shield (Kim et al., 1989) and Petlan, Mexico (Valdes et al., 1996). Randall (1973), Archuleta et al. (1982), and Fletcher et al. (1984) demonstrated that the slope of 1.0 for moment magnitude relations can be explained by the response of the Wood-Anderson instrument since the corner frequency of small events is greater than the cutoff frequency of $1.2 \mathrm{~Hz}$ Wood-Anderson instrument.

\section{Conclusions}

Seismic moment $M_{o}$, logarithm of the coda duration and the local magnitude empirical relations were derived for the aftershocks of 1992 Cairo earthquake source area, providing a simple and straightforward way to quantify the source strength $M_{o}$ through such relationships, which is superior to any magnitude scale. The resulting estimate of seismic moment, from local magnitudes and coda duration imply the following:

- Seismic moment and local magnitude data are consistent with $\log \left(M_{o}\right)=(0.96 \pm 0.05) M_{L}+$ $+(17.88 \pm 0.13)$. The rms precision in $\log \left(M_{o}\right)$ is 0.028 .

- Coda durations are related to seismic moment by the following linear relation: $\log \left(M_{o}\right)=$ $=(2.35 \pm 0.27) \log (D)+(16.33 \pm 0.48)$ with a rms precision of 0.05 in $\log \left(M_{o}\right)$.

The derived empirical relationships are valid only for Cairo earthquake source region (Dahshour) as recorded at KEG broadband station. Their significance is only available in the $3.5 \times 10^{19}$ to $1.6 \times 10^{21}$ dyne $\cdot \mathrm{cm}$ moment range and 1.7 to 3.4 local magnitude range. 


\section{REFERENCES}

Abou El Enein, K.M., H.M. Hussein, A.S. Abu El ATA and E.M. IвRAHIM (2000): Seismological aspects of the Cairo earthquake, 12 October 1992, Ann. Geofis., 43 (3), 485-504

AKI, K. (1966): Generation and propagation of $\mathrm{G}$ waves from the Niigate earthquake of June 16, 1964. Part 2. Estimating of earthquake movement, release energy, and stress-strain drop from $\mathrm{G}$ wave spectrum, Bull. Earthquake Res. Inst., Tokyo Univ., 44, 73-88.

Arculeta, R.J., E. CrRnswick, C. Muller and P. Spudich (1982): Source parameters of the 1980 Mammoth Lakes, California, earthquake sequence, J. Geophys. Res., 87, 4595-4607.

BAKUM, W.H. (1984) : Seismic moments, local magnitudes, and coda duration for earthquakes in Central California, Bull. Seismol. Soc. Am., 74, 439-458.

Chen, P. and H. Chen (1989): Scaling law and its applications to earthquake statistical relations, Tectonophysics, 166, 53-72.

Dessokey, M.M., H.M. Hussein, E.S. Abdelrahman and M.F ABDELWAHED (2000): Local magnitude, duration magnitude and seismic moment of Dahshour 1992 earthquake, Ann. Geofis., 43 (1), 95-103.

Fletcher, J.B., J. BoATwright, L. HARR, T.C. HanKs and A. MCGARR (1984): Source parameters of aftershocks of the Oroville, California earthquake, Bull. Seismol. Soc. Am., 74, 1101-1123.

Gardini, D., E. Boschi, S. Mazza, A. Morelli, D. Ben Sari, D. Najid, H. Benhallou, M. Bezzeghoud, H. Trabelsi, M. Hfaidh, R.M. Kebeasy and E.M. IBRAHIM (1992): Very-broad-band seismology in Northern Africa under the MEDNET project, Tectonophysics, 209, 17-30.

HANKs, T. and D. Boore (1984): Moment magnitude in theory and pratice, J. Geophys. Res., 89, 6229-6235.
Herrmann, R.B. and A. KiJKo (1983): Modeling some empirical vertical component $L_{g}$ relations, Bull. Seismol. Soc. Am., 73, 157-171.

Hussein, H.M. (1999): Source process of the October 12, 1992 Cairo earthquake, Ann. Geofis., 42 (4), 665-674.

KIM, W.Y., R. WAHLSTROM and M. USKI (1989): Regional spectral scaling relations of source parameters for earthquakes in the Baltic shield, Tectonophysics, 166, 151-161.

Matmoun, M.E., A. Meghaed, A. Hussein and M. MarZouK (1993): Preliminary Studies on the Dahshour Earthquake (National Research Institute of Astronomy and Geophysics, Cairo, Egypt), abstract.

NutTLI, O.W. (1986 ): Yield estimates of Nevada Test site explosions obtained from seismic $L_{g}$-waves, J. Geophys. Res., 91, 2137-2151.

RANDALL, M.J. (1973): The spectral theory of seismic sources, Bull. Seismol. Soc. Am., 64, 1133-1144.

SAVAGE, M.K. and R.P. MEYER (1985): Aftershocks of an $M=$ $=4.2$ earthquake in Hawaii and comparison with long term studies of the same volume, Bull. Seismol. Soc Am., 75 (3), 759-777.

ShAPIRA, A. and A. Hofstetter (1993): Source parameters and scaling relations of earthquakes in Israel, Tectonophysics, 217, 217-226.

Street, R.L., R.B. Herrmann and O.W. Nuttli (1975): Spectral characteristics of the $L_{g}$-wave generated by the central United States earthquakes, Geophys. J. R. Astron. Soc., 41, 51-63.

VALDES, C.M. and R.P. MEYER (1996): Spectral analysis and earthquake scaling of the Petatan earthquake $\left(M_{s}=\right.$ $=7.6$ ) aftershocks, recorded at stations along the Pacific Coast and between the coast and Mexico city, Pure Appl. Geophys., 147 (4), 631-656.

(received January 15, 2003; accepted November 4, 2003) 